\title{
Partial Replacement of Cement in Concrete with Sugarcane Bagasse Ash and its Behaviour in Aggressive Environments
}

\author{
G. Nithin Kumar Reddy ${ }^{1}$, G. Harsha Vardhan ${ }^{2}$, S. Vijaya Bhaskar Reddy ${ }^{3}$ \\ ${ }^{I}$ Department of Civil Engineering, Assistant profecer, Geethanjali College of Engineering \\ ${ }^{2}$ Department Civil engineering, B.Tech final year, Vardhaman College of Engineering \\ ${ }^{3}$ HOD, Department of civil engineering, C M R Technical Campus
}

\begin{abstract}
The researches has shown that every one ton of cement manufacture releases half ton of carbon dioxide, so there is an immediate need to control the usage of cement. On the hand materials wastes such as Sugar Cane Bagasse Ash is difficult to dispose which in return is environmental Hazard. The Bagasse ash imparts high early strength to concrete and also reduce the permeability of concrete. The Silica present in the Bagasse ash reacts with components of cement during hydration and imparts additional properties such as chloride resistance, corrosion resistance etc. Therefore the use of Bagasse ash in concrete not only reduces the environmental pollution but also enhances the properties of concrete and also reduces the cost. This project mainly deals with the replacement of cement with Bagasse ash in fixed proportions and analysing the effect of magnesium sulphate on SCBA blended concrete. The concrete mix designed by varying the proportions of Bagasse ash for $0 \%, 5 \%, 10 \%, 15 \%, 20 \%, 25 \%$ the cubes are been casted and cured in normal water and 5\% magnesium sulphate solution for ages of 7, 28 and 60 days, the properties like slump cone test and compaction factor test for fresh concrete and compressive strength for hardened concrete are verified and results are analysed.
\end{abstract}

\section{Introduction}

The present work is to carry out a detailed analysis of the Concrete mix designs for various grades of concrete (M35 and M40) with different percentages of SUGARCANE BAGASSE ASH $(0 \%, 5 \%, 10 \%, 15 \%$, $20 \%, 25 \%$ ). Cubes are subjected to normal chemical curing and Testing the specimens at various ages. Plotting graphs and comparing the compressive strengths of blended concrete cubes in normal and chemical curing. Ordinary Portland cement is the most commonly used building material throughout the world and it will retain its status in near future also because of demand and expansion of construction industry all over the world. Further the greatest challenge before the concrete construction industry is to serve the two pressing needs of human society, namely the protection of environment and meeting the infrastructure requirements of our growing population Structures which are constructed in aggressive environments are liable to be subjected to acidic attack. One of such major problems is sulphate attack against concrete structures due to which there will be loss of weight and reduction in strength of concrete. Contaminated ground water, seawater, industrial effluents are some of the sources of sulphate that attack on concrete. The use of blended cements have shown a sharp results in resisting the sulphate attack on concrete, sugarcane bagasse ash which shows pozzolanic properties is being used as a partial replacement in concrete in regular intervals of 5\% upto $25 \%$. SCBA is being produced from sugar manufacturing units as a waste material which will be grinded to the fineness less than cement for obtaining good bonding between cement and SCBA. This project discusses the very severe exposure of magnesium sulphate on concrete.

Bagasse is a by-product from sugar industries which is burnt to generate power required for different activities in the factory. The burning of bagasse leaves bagasse ash as a waste, which has a pozzolanic property that would potentially be used as a cement replacement material. It has been known that the worldwide total production of sugarcane is over 1500 million tons. Sugarcane consists about 30\% bagasse whereas the sugar recovered is about $10 \%$, and the bagasse leaves about $8 \%$ bagasse ash (this figure depend on the quality and type of the boiler, modern boiler release lower amount of bagasse ash) as a waste, this disposal of bagasse ash will be of serious concern. Sugarcane bagasse ash has recently been tested in some parts of the world for its use as a cement replacement material. The bagasse ash was found to improve some properties of the paste, mortar and concrete including compressive strength and water tightness in certain replacement percentages and fineness. The higher silica content in the bagasse ash was suggested to be the main cause for these improvements. Although the silicate content may vary from ash to ash depending on the burning conditions and other properties of the raw materials including the soil on which the sugarcane is grown, it has been reported that the silicate undergoes a pozzolanic reaction with the hydration products of the cement and results in a 
reduction of the free lime in the concrete. This attack is related to the expansive character of the ettringite formation by reaction of internal (in the concrete) or external (from the environment) sulphate with the hydrated calcium aluminate of the hardened cement matrix. Not necessarily the ettringite formation produces a damaging effect. When it occurs homogeneously and immediately (within hours or days) in a mixture or in a deformable concrete - early ettringite formation (EEF) - the related expansion does not cause any significant localized disruptive action. This happens when ground gypsum reacts with anhydrous calcium aluminates within some hours (set regulation) or when a calcium aluminate sulphate $\left(C_{4} A_{3} S\right)$ hydrates within few days producing a relatively small, homogeneous, harmless and rather useful stress. On the other hand, when ettringite forms heterogeneously and later (after months or years) - delayed ettringite formation (DEF) - the localized related expansion in a rigid hardened concrete produces cracking, spalling, and strength loss. There are two types of DEF- related damage depends on the sulphate source: external or internal sulphate attack.

Magnesium Sulphate is an inorganic salt (chemical compound) containing magnesium, sulphur and oxygen, with the formula $\mathrm{MgSO}_{4}$. It is often encountered as the heptahydrate sulphate mineral epsomite $\left(\mathrm{MgSO}_{4} \cdot 7 \mathrm{H}_{2} \mathrm{O}\right)$, commonly called Epsom salt, taking its name from a bitter saline spring in Epsom in Surrey,England, where the salt was produced from the springs that arise where the porous chalk of the North Downs meets non-porous London clay. The monohydrate, $\mathrm{MgSO}_{4} \cdot \mathrm{H}_{2} \mathrm{O}$ is found as the mineral kieserite. It is highly soluble in water. The anhydrous form is strongly hygroscopic, and can be used as a desiccant. Magnesium sulphate is the primary substance that causes the absorption of sound in seawater (acoustic energy is converted to thermal energy). Absorption is strongly dependent on frequency: lower frequencies are less absorbed by the salt, so that the sound travels much farther in the ocean.

\section{Literature Review}

Concrete when exposed to aggressive environments have a lot of effects and this is a very severe problem of the structures constructed nearer to sea, industries releasing gases containing excess sulphate content. Most of the concretes show effects like cracking, spalling, expansion of concrete and obviously loss in the strength. Blended cements show very sharp results restricting this sulphate attack, sugarcane bagasse ash being one of the blending materials which has shown a very good result in increase of strength and workability. This project deals with the effect of sulphates on concrete replaced partially with sugarcane bagasse ash.

\section{A. Material Used:}

\section{Experimental Investigation}

Cement- Ordinary Portland cement of 53 grade from a single batch was used for the entire work and care has been taken that it has to been stored in airtight containers to prevent it from being affected by the atmospheric and monsoon moisture and humidity. The cement procured was tested for physical requirements in accordance with IS:12269-1987 and for chemical requirements in accordance with IS: 4032-1977.

Sugarcane Bagasse Ash- Sugarcane bagasse consists of approximately 50\% of cellulose, 25\% of hemicelluloses of lignin. Each ton of sugarcane generates approximately $26 \%$ of bagasse (at a moisture content of 50\%) and $0.62 \%$ of residual ash. The residue after combustion presents a chemical composition dominates by silicon dioxide (sio2). In spite of being a material of hard degradation and that presents few nutrients, the ash is used on the farms as a fertilizer in the sugarcane harvests. In this sugarcane bagasse ash was collected during the cleaning operation of a boiler in the sugar factory.

Fine Aggregate- The river sand, passing through $4.75 \mathrm{~mm}$ sieve and retained on $600 \mu \mathrm{m}$ sieve, conforming to Zone II as per IS 383-1970 was used as fine aggregate in the present study. The sand is free from clay, silt and organic impurities. The aggregate was tested for its physical requirements such as gradation, fineness modulus, specific gravity and bulk modulus in accordance with IS:2386-1963.

Coarse Aggregate- Throughout the investigations,crushed coarse aggregates of $20 \mathrm{~mm}$ procured from the local crushing plants was used. The aggregate was tested for its physical requirements such as gradation, fineness modulus, specific gravity and bulk density etc. in accordance with IS:2386-1963 and IS:383-1970.

$\mathbf{M g S O}_{4}$ Solution- 5\% MgSo4 solution is prepared by adding 500 gms of MgSo4to 10 ltrs of diluted water. The ph value of 5\% MgSo4 solution was maintained between 6 to 9. The constant ph value was maintained throughout the study.

Table 1: Physical \& Chemical Properties of OPC, Sugarcane Baggase Ash.

\begin{tabular}{|c|c|c|}
\hline Properties & Ordinary Portland Cement & Sugarcane baggase ash \\
\hline \multicolumn{3}{|l|}{ Physical properties } \\
\hline Initial Setting Time (Min) & 115 & - \\
\hline Final Setting Time (Min) & 229 & - \\
\hline Specific Gravity & 3.15 & 2.12 \\
\hline
\end{tabular}

International Conference on Recent Innovations in Civil \& Mechanical Engineering 
Partial Replacement of Cement in Concrete with Sugarcane Bagasse Ash and its Behaviour in

\begin{tabular}{|l|l|l|}
\hline Fineness as Surface Area $(\mathrm{m} 2 / \mathrm{kg})$ & 370 & 410 \\
\hline Chemical Properties & \multicolumn{2}{|l|}{} \\
\hline Silicon Dioxide $(\mathrm{SiO} 2)$ & $21.02 \%$ & $70.97 \%$ \\
\hline AluminiumOxide $(\mathrm{Al} 2 \mathrm{O} 3)$ & $5.68 \%$ & $8.55 \%$ \\
\hline Ferric Oxide $(\mathrm{Fe} 2 \mathrm{O} 3)$ & $3.53 \%$ & $3.61 \%$ \\
\hline Magnesium Oxide $(\mathrm{MgO})$ & $1.1 \%$ & $2.83 \%$ \\
\hline Calcium Oxide $(\mathrm{CaO})$ & $62.25 \%$ & $6.50 \%$ \\
\hline Sulphur Trioxide $(\mathrm{SO} 3)$ & $3.0 \%$ & $0.80 \%$ \\
\hline Sodium Oxide $(\mathrm{Na2O})$ & $0.15 \%$ & $0.92 \%$ \\
\hline Potassium Oxide $(\mathrm{K} 2 \mathrm{O})$ & $0.35 \%$ & $1.77 \%$ \\
\hline Loss of Ignition & $1.05 \%$ & $2.56 \%$ \\
\hline
\end{tabular}

\section{B. Mix Proportions of Specimen:}

The mixture proportions of all specimens for replacement of Sugarcane Baggase Ash are tabulated respectively at Table 2. The replacement levels of cement by SCBA were selected as 0\% (control mix), 5\%, $10 \%, 15 \%, 20 \%$ and $25 \%$. For all specimens, water/binder (w/b) ratio was kept constant and it was 0.48 where the total amount of binder content was $480 \mathrm{Kg} / \mathrm{m} 3$ for every specimen. The mixture proportions of Binder: Fine Aggregate: Coarse Aggregate was taken as 1: 1.28: 2.2.

\section{Mechanism of Sulphate Attack:}

Calcium Hydroxide and Alumina-bearing phase of hydrated cement are more vulnerable to attack by Sulphate ions. Ettringite and Gypsum are the primary products of the chemical reaction between a Sulphate bearing solution and cement hydration products. Failure by expansion of concrete in the presence of Sulphate is due to the formation of Ettringite. The attack of Sodium Sulphate on concrete is due to two principal reactions: the reaction of Sodium Sulphate $\left[\mathrm{Na}_{2} \mathrm{SO}_{4}\right]$ or Magnesium Sulphate $\left[\mathrm{MgSO}_{4}\right]$ and Calcium Hydroxide $[(\mathrm{Ca}(\mathrm{OH}) 2]$ to form Gypsum (Equations 1.1 and 1.2) and the reaction of the formed Gypsum with Calcium Aluminate Hydrates to form Ettringite (Equation 1.3). In addition to above, the Magnesium Sulphate reacts with all cement compounds, including Calcium Silicate Hydrates [C-S-H] and subsequently forming Gypsum and Ettringite (Equation1.4). The Magnesium Hydroxide reacts with silica gel to form Magnesium Silicate Hydrate $[\mathrm{M}-\mathrm{S}-\mathrm{H}]$, being a soft material and affects the strength and durability of concrete. The form of Ettringite developed in the cement paste is depending on phase of Calcium Aluminate Hydrates, which reacts with Sulphate. In the fresh concrete, the Gypsum, which is blended to prevent flash set, reacts with Calcium Aluminate Hydrates to form primary Ettringite [C3As3H32]. This primary Ettringite is converted to Monosulphate [C3AsH32] with time.

The chemical reactions associated withSulphate attack are as follows:

$$
\begin{aligned}
& \mathrm{Na}_{2} \mathrm{SO}_{4}+\mathrm{Ca}(\mathrm{OH})_{2}+2 \mathrm{H} 2 \mathrm{O} \Rightarrow \mathrm{CaSO}_{4} .2 \mathrm{H} 2 \mathrm{O}+2 \mathrm{NaOH}-
\end{aligned}
$$

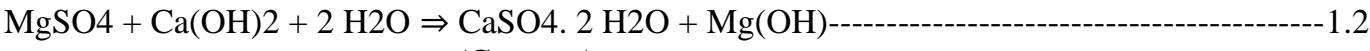

$$
\begin{aligned}
& \text { (Gypsum) }
\end{aligned}
$$

3CaO. $\mathrm{Al} 2 \mathrm{O} 3$.12H2O+ 3(CaSO4. $2 \mathrm{H} 2 \mathrm{O})+13 \mathrm{H} 2 \mathrm{O} \Rightarrow$ 3CaO.Al2O3..3CaSO4.31H2O---------- 1.3 (Ettringite)

$\mathrm{Mg} \mathrm{SO} 4+\mathrm{C}-\mathrm{S}-\mathrm{H} \Rightarrow \mathrm{CaSO} 4.2 \mathrm{H} 2 \mathrm{O}+\mathrm{M}-\mathrm{S}-\mathrm{H}$

Table 2: Mix Proportions for Sugarcane Baggase Ash

\begin{tabular}{|l|l|l|l|l|l|}
\hline Specimen & w/b Ratio & Cement $(\mathrm{Kg} / \mathrm{m} 3)$ & \multicolumn{2}{|l|}{$\mathrm{SCBA}$} & \multirow{2}{*}{ Water $\mathrm{Kg} / \mathrm{m}^{3}$} \\
\cline { 4 - 5 } & & & $\%$ & $\mathrm{Kg} / \mathrm{m}^{3}$ & \\
\hline $\mathrm{C}_{0}$ & 0.48 & 480 & $0 \%$ & 0 & 230.4 \\
\hline $\mathrm{C}_{1}$ & 0.48 & 456 & $5 \%$ & 24 & 230.4 \\
\hline $\mathrm{C}_{2}$ & 0.48 & 432 & $10 \%$ & 48 & 230.4 \\
\hline $\mathrm{C}_{3}$ & 0.48 & 408 & $15 \%$ & 72 & 230.4 \\
\hline $\mathrm{C}_{4}$ & 0.48 & 384 & $20 \%$ & 96 & 230.4 \\
\hline $\mathrm{C}_{5}$ & 0.48 & 360 & $25 \%$ & 120 & 230.4 \\
\hline
\end{tabular}




\section{Casting of Specimen and Curing:}

Mixing of ingredients is done in pan mixer of capacity 40 liters. The cementitious materials are thoroughly blended and then the aggregate is added and mixed followed by gradual addition of water and mixing. Wet mixing is done until a mixture of uniform color and consistency are achieved which is then ready for casting. Before casting the specimens, workability of the mixes was found by compaction factor test. The casting is done in cast iron cubes of standard dimensions of $(150 \mathrm{~mm} \times 150 \mathrm{~mm} \times 150 \mathrm{~mm})$. The cast iron moulds are cleaned of dust particles and applied with mineral oil on all sides before concrete is poured in to the moulds. The moulds are placed on a level platform. The well mixed concrete is filled in to the moulds and kept on vibration table. Excess concrete was removed with trowel and top surface is finished level and smooth as per IS 516-1969.

Curing-The specimens are left in the moulds undisturbed at room temperature for about 24 hours after casting. The specimens are then removed from the moulds and immediately transferred to the different curing environment tubs i.e. cubes are cured in fresh water and 5\% MGSO4 diluted solution. A time schedule for testing of specimens is maintained to ensure their proper testing on the due date and time. The cast specimens are tested as per standard procedures, immediately after they are removed from curing tubs and wiped off the surface water, as per IS 516-1959.

\section{E. Tests Conducted:}

Workability- The workability was measured using slump cone and compaction factor apparatus for different percentage replacement of cement with sugarcane bagasse ash in concrete.

Compressive Strength of Concrete Specimens-Concrete specimens are casted to determine the compressive strength of different weight percentages of sugarcane bagasse ash concrete as per IS 516- 1969.

Durability- The durability of sugarcane bagasse ash concrete was tested for resistance $5 \% \mathrm{MgSO}_{4}$ diluted solution. The response of chemical attack on different percentage replacement of cement with sugarcane bagasse ash in concrete was studied by reduction in compressive strength. For conducting these tests, concrete cubes of $150 \mathrm{~mm} \times 150 \mathrm{~mm} \times 150 \mathrm{~mm}$ size with ordinary and different percentage replacement of cement with sugarcane bagasse ash were cast. These cubes were immersed in a $\mathrm{MgSO}_{4}$ solution by maintaining 8.3 ph value for different periods of 7,28 and 60days.

\section{Durability studies on Cement Conventional Concrete \& Sugar Cane Bagasse Ash Concrete:}

Concrete is the most versatile material of construction the world over. It is achieved that the distinction of being the "largest man-made material" with the average per capita consumption exceeding $2 \mathrm{~kg}$. Concrete is the material of choice for a variety of applications such as housing, bridges, highway pavements, industrial structures, water carrying and retaining structures etc. The credit for this achievement goes to well-known advantages of concrete such as easy availability of ingredients, adequate engineering properties for a variety of structural applications, adaptability, versatility, relative low-cost etc. Moreover, concrete has an excellent ecological profile compared with other materials of construction. With the continuing expansion of infrastructure and housing construction, especially in the developing countries of Asia, Africa, and South America, the rate of consumption of cement and concrete is rising and is bound to go further. In India, concrete construction scenario has been witnessing considerable growth in recent years.

\section{Results And Discussions}

Concrete cubes of size $100 \times 100 \times 100 \mathrm{~mm}$ were casted and tested for compressive strength in normal water and $5 \%$ magnesium sulphate solution at ages of 7, 28, 60 days for $0 \%, 5 \%, 10 \%, 15 \%, 20 \%, 25 \%$ replacement of sugarcane bagasse ash for M35 and M40 grades of concrete. In order to study the durability of SCBA replaced concrete in 5\% magnesium sulphate solution concrete cubes were casted and tested to find out the effect of magnesium sulphate solution on compressive strength of concrete.

Table 3: Compressive Strength Results (M35 in normal water)

\begin{tabular}{|l|l|l|l|l|}
\hline Specimen ID & \% of SCBA in Cement & At 7 days $\left(\sigma_{7}\right)$ & At 28 days $\left(\sigma_{28}\right)$ & At 60 days $\left(\sigma_{60}\right)$ \\
\hline C0 & 0 & 35 & 41.05 & 49.6 \\
\hline C1 & 5 & 39 & 45.33 & 54.38 \\
\hline C2 & 10 & 37.5 & 51.3 & 55.66 \\
\hline C3 & 15 & 35.5 & 48.5 & 47.5 \\
\hline C4 & 20 & 31.66 & 44.83 & 45.33 \\
\hline C5 & 25 & 32.66 & 43.66 & 42 \\
\hline
\end{tabular}


Table 4: Compressive Strength Results (M35 in 5\% $\left.\mathrm{MgSo}_{4}\right)$

\begin{tabular}{|l|l|l|l|ll|}
\hline $\begin{array}{l}\text { Specimen } \\
\text { ID }\end{array}$ & $\begin{array}{l}\text { \% SCBA in } \\
\text { Cement }\end{array}$ & $\begin{array}{l}\text { At 7 days } \\
\left(\sigma_{7}\right)\end{array}$ & $\begin{array}{l}\text { At 28 } \\
\text { days }\left(\sigma_{28}\right)\end{array}$ & $\begin{array}{l}\text { At 60 days } \\
\left(\sigma_{60}\right)\end{array}$ \\
\hline C0 & 0 & 29.7 & 40 & 45.86 & \\
\hline C1 & 5 & 32.5 & 43.5 & 51 \\
\hline C2 & 10 & 38 & 49.55 & 53.1 \\
\hline C3 & 15 & 37 & 47 & 46 \\
\hline C4 & 20 & 34 & 43.6 & 44.5 \\
\hline C5 & 25 & 32 & 43 & 41.44 \\
\hline
\end{tabular}

\section{Consolidated Tabels \& Graphs of Concret under Normal Conditions and Aggressive Conditions:}

Table 5:- Reduction in Compressive strength under $5 \% \mathrm{MgSo}_{4}$ at 7 days

\begin{tabular}{|l|l|l|l|l|}
\hline $\begin{array}{l}\text { Specimen } \\
\text { ID }\end{array}$ & $\begin{array}{l}\text { \% of SCBA in } \\
\text { Cement }\end{array}$ & $\left(\square_{\mathbf{c u}}\right)$ & $\left(\square_{\text {cu }}\right)$ & $\begin{array}{l}\% \\
\text { reduction }\end{array}$ \\
\hline M0 & 0 & 35 & 34 & 2.85 \\
\hline M1 & 5 & 39 & 38.2 & 2.05 \\
\hline M2 & 10 & 37.5 & 36.8 & 1.33 \\
\hline M3 & 15 & 35.5 & 35.22 & 0.78 \\
\hline M4 & 20 & 31.66 & 31.5 & 0.5 \\
\hline M5 & 25 & 32.66 & 32.5 & 0.48 \\
\hline
\end{tabular}

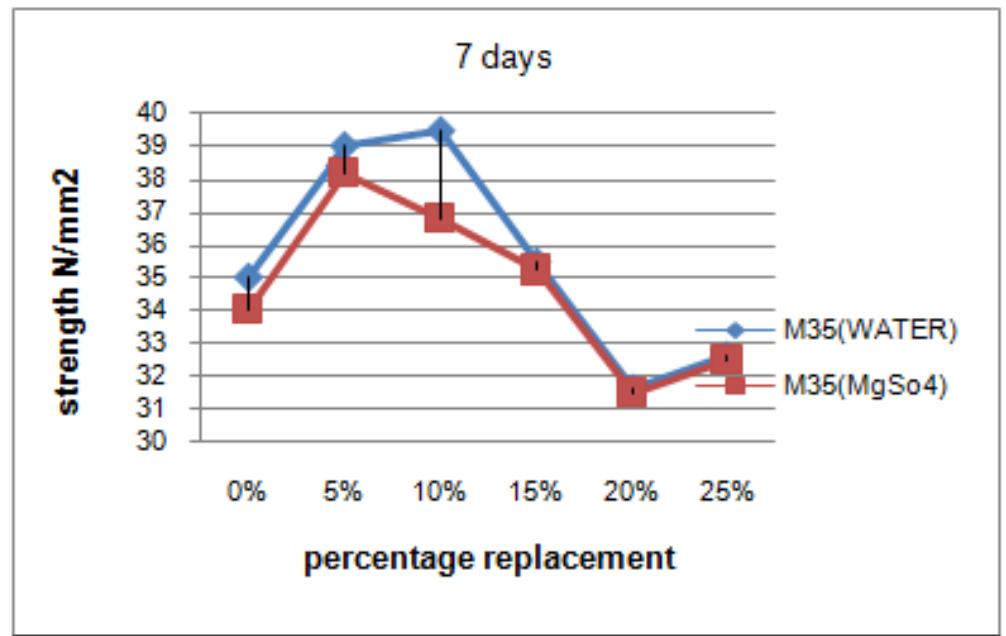

Fig 1: Consolidated compressive strength results of specimens exposed to normal and aggressive environments at the age of 7 days

Fig 1.shows the compressive strength results of cement concrete in which cement is partially replaced with sugarcane bagasse ash under normal conditions and which is exposed to $5 \% \mathrm{MgSo}_{4}$ solution at the age of 7 days. The results indicate that the compressive strength of concrete increases up to a percentage replacement of $10 \%$ after which there is a gradual drop in compressive strength.

Table 6: Reduction in Compressive strength under $5 \% \mathrm{MgSo}_{4}$ at 28 days

\begin{tabular}{|l|l|l|l|l|}
\hline $\begin{array}{l}\text { Specimen } \\
\text { ID }\end{array}$ & $\begin{array}{l}\text { \% of SCBA } \\
\text { in Cement }\end{array}$ & $\left(\sigma_{\mathrm{cu}}\right)$ & $\left(\sigma_{\mathrm{cu}}\right)$ & $\%$ reduction \\
\hline M0 & 0 & 42.66 & 40 & 6.23 \\
\hline M1 & 5 & 45.33 & 43.5 & 4.03 \\
\hline M2 & 10 & 51.3 & 49.55 & 3.41 \\
\hline M3 & 15 & 48.5 & 47 & 3.09 \\
\hline M4 & 20 & 44.83 & 43.6 & 2.74 \\
\hline M5 & 25 & 43.66 & 43 & 1.51 \\
\hline
\end{tabular}




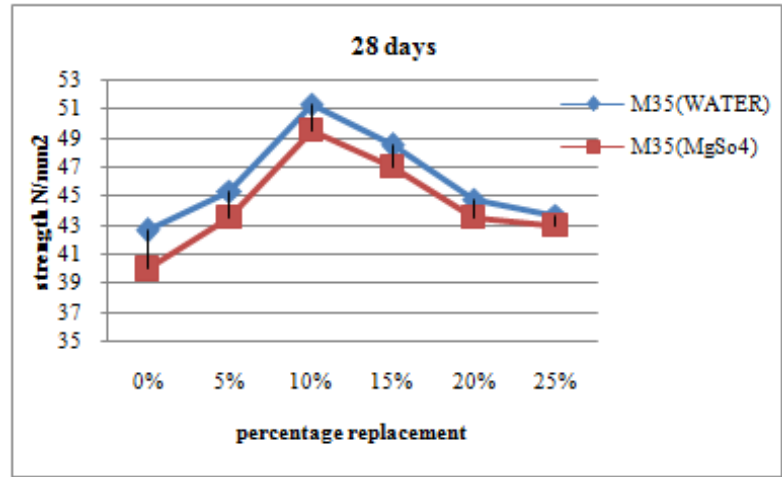

Fig 2: Consolidated compressive strength results of specimens exposed to normal and aggressive environments at the age of 28 days

Fig 2 shows the compressive strength results of cement concrete in which cement is partially replaced with sugarcane bagasse ash under normal conditions and which is exposed to $5 \% \mathrm{MgSo}_{4}$ solution at the age of 28 days. The results indicate that the compressive strength of concrete increases up to a percentage replacement of $10 \%$ after which there is a gradual drop in compressive strength.

Table 7: Reduction in Compressive strength under $5 \% \mathrm{MgSo}_{4}$ at 60 days

\begin{tabular}{|l|l|l|l|l|}
\hline $\begin{array}{l}\text { Specimen } \\
\text { ID }\end{array}$ & $\begin{array}{l}\text { \% of SCBA } \\
\text { in Cement }\end{array}$ & $\left(\square_{\mathbf{c u}}\right)$ & $\left(\square_{\mathbf{c u}}\right)$ & $\%$ reduction \\
\hline M0 & 0 & 49.6 & 45.86 & 7.54 \\
\hline M1 & 5 & 54.38 & 51 & 6.62 \\
\hline M2 & 10 & 55.66 & 53.1 & 4.77 \\
\hline M3 & 15 & 47.5 & 46 & 3.15 \\
\hline M4 & 20 & 45.33 & 44.5 & 1.83 \\
\hline M5 & 25 & 42 & 41.44 & 1.33 \\
\hline
\end{tabular}

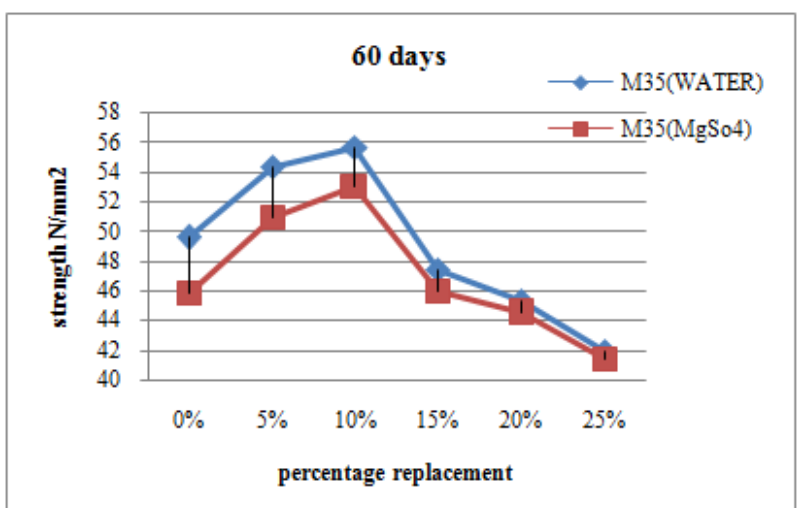

Fig 3: Consolidated compressive strength results of specimens exposed to normal and aggressive environments at the age of 60 days

Fig 3 shows the compressive strength results of cement concrete in which cement is partially replaced with sugarcane bagasse ash under normal conditions and which is exposed to $5 \% \mathrm{MgSo}_{4}$ solution at the age of 28 days. The results indicate that the compressive strength of concrete increases up to a percentage replacement of $10 \%$ after which there is a gradual drop in compressive strength.

\section{Conclusions}

- SCBA concrete performed better when compared to ordinary concrete up to $10 \%$ replacement of sugar cane bagasse ash due to presence of high amount of silica in SCBA

- Compressive strength was decreased when cured in $5 \% \mathrm{MgSo}_{4}$ comparatively when cured in normal water.

- It is observed that the usage of sugarcane bagasse ash in concrete helps in increasing the resistivity towards sulphate attack.

- The percentage reduction in compressive strength was decreasing with increase in percentage replacement of sugarcane bagasse ash when cured in $5 \% \mathrm{MgSo}_{4}$ which concludes that SCBA helps in resisting the concrete towards sulphate attack. 


\section{References}

[1] Mrs.U.R.Kawade, Mr.V.R.Rathi, Miss Vaishali D Girge "Effect of use of Bagasse Ash on Strength of Concrete" International Journal of Innovative Research in Science, Engineering and Technology Vol. 2, Issue 7, July 2013.

[2] R.Srinivasan, K.Sathiya "Experimental Study on Bagasse Ash in Concrete” International Journal for Service Learning in Engineering, Vol. 5, No. 2, Fall 2010.

[3] Lavanya M.R, Sugumaran.B, Pradeep.T "An Experimental study on the compressive strength of concrete by partial replacement of cement with sugarcane bagasse ash" International Journal of Engineering Inventions, Volume 1, Issue 11 (December2012).

[4] Biruk Hailu And Abebe Dinku "Application Of Sugarcane Bagasse Ash As A Partial Cement Replacement Material".

[5] Kanchan Lata Singh, S.M.Ali Jawaid "A Review Onutilization Of Sugarcane Bagasse Ash (Scba) As Pozzolanic Material In Concrete” Ijbstr Reviewpaper, Vol 1 [Issue 8] August 2013.

[6] Nigarik Dave "A Review Oneffect Of Sulphate Attack On Properties Of Concrete” International Journal Of Emerging Trends In Engineering And Development, Issue 3, Vol.1 (January 2013).

[7] N.R.Dakshina Murthy Et Al., "Studies On Fly Ash Concrete Under Sulphate Attack In Ordinary, Standard And Higher Grades At Earlier Ages" Asian Journal Of Civil Engineering (Building And Housing), Vol. 8, No. 2 (2007).

[8] J. Prasad Et Al., "Factors Influencing The Sulphate Resistance Of Cement Concrete And Mortar" Asian Journal Of Civil Engineering (Building And Housing), Vol. 7, No. 3 (2006).

[9] Akaninyene A. Umoh and Kolapo O. Olusola "Effect of Different Sulphate Types and Concentrations on Compressive Strength of Periwinkle Shell Ash Blended Cement Concrete" International Journal of Engineering \& Technology IJET-IJENS Vol:12 No:05.

[10] Behrouz Mohebimoghaddam "The effects of sulfate solution on the behavior of reinforced concrete beams" Electronic Journal of Structural Engineering, 6 (2006).

[11] A.Aielstein Rozario et al., "Experimental Studies on Effects of Sulphate Resistance on Self-Curing Concrete" International Journal of Engineering Research \& Technology (IJERT), Vol. 2 Issue 4, April - 2013.

[12] M. M. Amin et al., "Effects of Magnesium Sulfate Attack on Ordinary Portland Cement (OPC) Mortars" Portugaliae Electrochimica Acta 26 (2008).

[13] D.Govindarajan and G.Jayalakshmi “XRD, FTIR and SEM studies on calcined sugarcane bagasse ash blended cement" 